\title{
TEATRO NA EDUCAÇÃO: AVANÇOS, LIMITES E CONTRADIÇÕES
}

\author{
José Marcio Nerone Leite ${ }^{1}$ \\ Juliana de Castro Chaves ${ }^{2}$
}

\section{Resumo}

O teatro é uma expressão artística e toda arte é manifestação da cultura. Este trabalho faz uma pequena discussão da arte a partir da Teoria Crítica da Sociedade, e mais especialmente de Theodor Adorno, Herbert Marcuse e Walter Benjamin, que oferecem contribuiçóes para pensarmos a arte e o teatro como uma manifestação da cultura que realiza a formação, um conhecimento que é fundamento da educação, e que por isso não devia ser instrumentalizado. Este trabalho faz um levantamento do processo de como a arte foi implantada na educação escolar nos ensinos infantil, fundamental, médio e superior, na LDB e nos PCN no sentido de entender os elementos principais que a legislação aponta para o ensino da arte e, posteriormente, realiza algumas ponderaçóes sobre esse processo de institucionalização da arte no Brasil. As reflexóes aqui contidas fazem parte da dissertação de mestrado "Estudos sobre o ensino do teatro na escola e a apropriação da teoria crítica", desenvolvida por José Marcio Nerone Leite no Programa de Pós-Graduação em Educação da Faculdade de Educação/FE da Universidade Federal de Goiás, no convênio MINTER em Educação UFG/IFMT 2015, defendida em 2018.

Palavras-chave: Institucionalização. Ensino e arte. Teatro e escola.

1 Mestre em Educação pela UFG e professor efetivo do IFMT - Campus São Vicente. E-mail: jose. nerone@svc.ifmt.edu.br

2 Doutora em Psicologia Social, professora adjunta do Programa de Pós-Graduação em Educação da Faculdade de Educação e do curso de Psicologia da Universidade Federal de Goiás. E-mail: julichcastro@gmail.com 


\section{Introdução}

Pensar na formação é pensar na cultura, ou seja, como ela é subjetivada ou como é produzida. Para Benjamin (1994), a cultura precisa produzir um sistema no qual as práticas sociais e os sistemas simbólicos deem garantia da articulação das particularidades humanas e sociais dos sujeitos. Segundo Adorno (1996), a cultura é a apropriação subjetiva do sujeito em sociedade. Apropriar-se da cultura é exercer a humanidade.

Nesse sentido, a cultura tende a ser uma produçáo subjetiva da humanidade, ela faz parte da constituição humana e é constituída pelo sujeito (ADORNO; HORKHEIMER, 1985). "A formaçáo nada mais é que a cultura tomada pelo lado de sua apropriação subjetiva”. Ou seja, a cultura possibilita a formação se é manifestação da práxis humana (ADORNO, 1995, p. 9).

Para Marcuse (1998), Adorno (1996) e Benjamin (2012), a arte e o teatro são manifestaçôes da cultura. Essas manifestaçōes culturais podem ser formativas, ser objeto de resistência à lógica do capitalismo da indústria cultural. Nesse sentido elas náo são meio para algo, ou seja, elas náo devem ser tomadas como pedagogia para aprendizagem de conteúdos específicos, serem consideradas didática que prende a atenção e que provoca envolvimento, não possuem uma finalidade externa, ou seja, não têm a função de resultar em um produto, um espetáculo, para a apresentaçáo em datas festivas, elas náo sáo uma linguagem, mas um fundamento da educaçáo, uma forma de conhecimento que apresenta uma forma estética que revela as contradiçōes da sociedade.

A arte transcende o presente como processo histórico e pressupóe a recusa de um curso predeterminado da história, podendo trazer a memória do passado não como algo fixado e determinado que garante a continuidade de um determinado curso (ADORNO, 1995).

O teatro, segundo Marcuse (1973), é uma das expressóes artísticas que pode conter elementos de resistência diante de uma realidade que oculta as suas mediaçóes. Pode existir rebeliáo no teatro. Marcuse (1973, p. 78) lembra que Bertolt Brecht afirmava que o teatro devia romper com a identificação do espectador, com os acontecimentos no palco para transparecer o que o mundo é. Nesse sentido:

Não são necessários empatia e sentimentos, mas distância e reflexão. O efeito de alheamento deve produzir a dissociação. 
[...] As coisas da vida cotidiana são elevadas para fora do reino do que é evidente por si... O que é "natural" deve assumir as particularidades do que é extraordinário.

Feita essa breve discussão sobre arte e teatro, em seguida apresentamos o processo de institucionalização da arte, e mais especialmente do teatro na educação escolar a partir dos documentos da LDB e dos PCN, no sentido de entender os elementos principais que a legislaçáo aponta para o ensino da arte.

\section{Arte e teatro na educação}

Berthold (2000, p. 1) afirma que "o teatro é tão velho como a humanidade" e desde a sua origem de tradição greco-romana é reconhecido como manifestação artística capaz de educar e instruir. No Brasil, dá-se a entender que as primeiras manifestações de práticas teatrais se dão no século XVI, nas composiçóes teatrais escritas pelos padres Jesuítas nas açôes de catequização da fé religiosa aos índios.

Nesse contexto, o teatro tinha o teor de ser um meio de doutrinação mais agradável, diferentemente dos sermóes. Com a chegada da corte portuguesa no século XIX a arte de representar se desenvolve de forma mais intensa (MAGALDI, 1978). Para essas primeiras manifestaçôes, as expressōes artísticas eram rotineiras, sem vinculação com a construção do conhecimento, ou seja, da liberdade de expressão à liberdade num todo.

Há predominância da tendência tradicional no processo de ensino das artes. Essa tendência está presente no século XIX e percorreu todo o século XX. A teoria estética mimética em que os professores apresentam modelos para os alunos imitarem, um padráo de beleza que valoriza a melhor reprodução, significando que quanto mais próximo do real, do modelo, mais se considera bonito, é preponderante nessa vertente (FUSARI; FERRAZ, 2001).

Pode-se afirmar que a legalização da atividade artística, da educação artística e do ensino de artes na escola aconteceram na esteira de discussóes de concepções de teatro e de educação práticas do teatro no âmbito educacional mais geral. Na primeira metade do século XX, as disciplinas Desenho, Trabalhos Manuais, Música e Canto Orfeônico faziam parte dos programas das escolas primárias e secundárias privilegiando a transmissão de padróes e modelos das classes sociais dominantes e a preparaçáo das classes sociais 
baixas para os trabalhos manuais. Valorizavam-se as habilidades manuais, os dons, os hábitos de organização e precisão. Nesse contexto, os professores trabalhavam com exercícios e modelos convencionais de manuais e livros didáticos (BRASIL, 2000).

As atividades de teatro [...] não estavam incluídas no currículo escolar como práticas obrigatórias, e somente eram reconhecidas quando faziam parte das festividades escolares na celebração de datas como Natal, Páscoa ou Independência, ou nas festas de final de período escolar. [...] Os alunos decoravam os textos e os movimentos cênicos eram marcados com rigor. Apesar da rigidez gestual e vocal dessa atividade, a relação com a platéia era de alguma forma contemplada, tanto que se privilegiava a aprendizagem da diç̧ão. (BRASIL, 1998, p. 23-4).

Na década de 30 do século XX, a prática do jogo dramático desenvolvida pela Psicologia e realçada pela Escola Nova é introduzida na escola como recurso didático para o ensino de conteúdos escolares como Português, Geografia e História.

Essa possibilidade de ensino é denominada, no campo acadêmico, como corrente contextualista por utilizar a arte como instrumento de ensino para outras áreas. A possibilidade do teatro trabalhar objetivos amplos, como o estímulo à criatividade, à desinibição, ao desenvolvimento da atenção e concentração faz parte dessa concepção instrumentalista de ensino, que vê na arte um caráter utilitário, acreditando que o ensino das artes deve servir para a formação de valores, atitudes e hábitos (BRASIL, 2000, não paginado).

No caldo desse processo, com a contribuição das linguagens artísticas, delineou-se uma perspectiva essencialista de arte. Segundo Japiassu (2001, p. 28):

A partir da década de 50, no Brasil, o campo de pesquisas e discussóes a respeito do teatro na educação se amplia através de novas propostas das práticas teatrais. Com a influência de Her- 
bert Read, filósofo inglês que desenvolveu a ideia da educação através da arte, isto é, ver a arte não apenas como um auxílio da educação, mas, reconhecê-la pelo seu processo que possibilita o conhecimento, o teatro começa a ser pensado na educação escolar de uma forma a superar seu uso como ferramenta para alcançar conteúdos extrateatrais. Essa abordagem pedagógica da arte-educação é chamada corrente essencialista ou estética, que acredita na importância da arte em si mesma, como forma de representação simbólica para a comunicação do pensamento e sentimento humanos. Nesse caso, o teatro é um importante meio de comunicação e expressão, sendo reconhecido como forma de conhecimento capaz de mobilizar e coordenar as dimensóes sensório-motora, simbólica, afetiva e cognitiva do educando, tornando-se útil na compreensão crítica da realidade humana culturalmente determinada.

Nessa perspectiva, a função educacional do teatro fica ligada a sua natureza estética, a sua expressividade e a busca do aprimoramento de sua forma artística. A educação essencialista não objetivava a formação de artistas, mas o domínio, a fluência e a compreensão estética das complexas formas humanas de expressão que movimentam processos afetivos, cognitivos e psicomotores (JAPIASSU, 2001).

Ela buscava a sensibilidade, a criatividade, a ludicidade e a liberdade de expressão se contrapondo à educação tradicional (REVERBEL, 1997). Para tanto, essa corrente considerava a arte em si mesma e não as suas possibilidades instrumentais. "O valor primeiro da arte reside na contribuição única que traz para a experiência individual e para a compreensão do homem" (KOUDELA, 1984, p.17, 18).

A primeira Lei de Diretrizes e Bases (LDB), Lei 4024/61, sistematizou o currículo e as matérias fazendo a divisão dos ensinos fundamental e médio, legislando que, no fundamental, o desenho, que mais se aproximava da dimensão artística, fosse delineado como matéria. No ensino médio, as atividades artísticas foram consideradas como uma atividade complementar, optativa, ou seja, ainda não obrigatória (BRASIL, 1961).

Em 1971 foi sancionada a Lei de Diretrizes e Bases da Educação Nacional (LDBN), que inclui a Educação Artística no currículo como "atividade edu- 
cativa” e não disciplina escolar, uma atividade extra sem comprometimento com notas, tratando de maneira indefinida esse conhecimento. Além de Educação Artística, a Lei 5692/1971 inclui Moral e Cívica, Educação Física e Programa de Saúde nos currículos do ensino de $1^{\circ}$ e $2^{\circ}$ graus.

A atividade educativa é considerada uma atividade polivalente, exigindo que o professor fosse detentor dos saberes como Música, Artes Plásticas e Teatro (BRASIL, 1971).

De maneira geral, entre os anos 70 e 80 os antigos professores de Artes Plásticas, Desenho, Música, Artes Industriais, Artes Cênicas e os recém-formados em Educação Artística viram-se responsabilizados por educar os alunos (em escolas de ensino fundamental) em todas as linguagens artísticas, configurando-se a formação do professor polivalente em arte. Com isso, inúmeros professores tentaram assimilar e integrar as várias modalidades artísticas, na ilusão de que as dominariam em seu conjunto. Essa tendência implicou a diminuição qualitativa dos saberes referentes às especificidades de cada uma das formas de arte e, no lugar destas, desenvolveu-se a crença de que o ensino das linguagens artísticas poderia ser reduzido a propostas de atividades variadas que combinassem Artes Plásticas, Música, Teatro e Dança, sem aprofundamento dos saberes referentes a cada uma delas. Com a polivalência as linguagens artísticas deixaram de atender às suas especificidades, constituindo-se em fragmentos de programas curriculares ou compondo uma outra área. (BRASIL, 1998, p. 26, 27).

Segundo o documento dos PCN de Arte (1998), essa inserção é considerada uma conquista, pois dá uma sustentação legal para o ensino na escola. Nessa perspectiva, o ensino de arte passa a ser concebido como uma linguagem para a educação. No entanto, outras apreensóes desse processo apontam algumas contradiçóes dessa implantação:

Foi nesse contexto [com a adoção da Lei no 5.692/71] que o ensino de arte entrou em cena oficialmente na educação brasileira, com o advento da Educação Artística para o ensino de $1^{\circ}$ e $2^{\circ}$ graus e do curso de Licenciatura em Educação Artística 
para o ensino superior, nos formatos de duração curta e plena [...] Isso se deu quer pela concepção pedagógica equivocada - a de fusão polivalente das linguagens artísticas, "conceito" que tentava abrigar um ensino pretensamente "interdisciplinar" das artes cênicas, plásticas, música e desenho, ministrado por um mesmo professor, da $1^{\mathrm{a}}$ a $8^{\mathrm{a}}$ série do $1^{\mathrm{o}}$ grau - , quer pela inadequação física das escolas ou então pela necessidade que se impôs quanto à improvisação de professores, provenientes das demais disciplinas, para preencher as lacunas criadas pela nova atividade escolar, já que não havia professor qualificado para tal. Formou-se, assim, uma verdadeira confusáo que passava pela questáo da competência profissional, do enfoque teórico-metodológico, das técnicas e materiais didáticos, como pelo próprio preconceito dos professores das outras disciplinas quanto à incompreensão da arte como forma de conhecimento, o que infelizmente perdura até hoje. (RIBEIRO, 2009, p. 89).

Por volta das décadas de 1980 e 1990, mais precisamente em 1988, a educação artística recebeu certa ênfase com o desenvolvimento de pesquisas acadêmicas que investigavam, dentre alguns temas, o modo de aprender dos artistas. Esse debate também influenciou a realização de discussóes sobre o papel da educação artística no âmbito escolar. Nesse contexto, a educaçáo artística propunha uma educaçáo estética que não fosse baseada no modelo homogêneo, mas na apreciação de cânones de diversas culturas e do cotidiano (BRASIL, 2000).

Na LDB 9.394/96 o ensino de Arte institui-se como disciplina obrigatória na educação básica, substituindo a Educação Artística promulgada pela LDB 5.692/71. A LDB no 9.394/96 tornou obrigatório o ensino de Arte na Educação Infantil, no ensino fundamental e no ensino médio. O art. 26, $\$ 2^{\circ}$ afirma: "o ensino da arte, especialmente em suas expressóes regionais, constituirá componente curricular obrigatório da educação infantil e do ensino fundamental, de forma a promover o desenvolvimento cultural dos alunos" (BRASIL, 1996).

Essa inferência pode ser feita a partir da reflexão que o professor tenha com a turma, já que: 
A arte na escola já foi considerada matéria, disciplina, atividade, mas sempre mantida à margem das áreas curriculares tidas como mais "nobres". Esse lugar menos privilegiado corresponde ao desconhecimento, em termos pedagógicos, de como se trabalhar o poder da imagem, do som, do movimento e da percepção estética como fontes de conhecimento. (BRASIL, 1998, p. 26).

Segundo o documento, o ensino ainda devia priorizar a liberdade de aprender, ensinar, pesquisar, divulgar a cultura, o pensamento, a arte, o saber e a valorização da experiência extraescolar (BRASIL, 1996).

O teatro, bem como as demais expressões artísticas, está presente e garantido por lei. A LDB, Lei 9.394/96, refere-se à educação estética e a obrigatoriedade do ensino de arte nos diversos níveis da educação básica (JAPIASSU, 2001). De acordo com a lei, não há especificamente a palavra teatro, mas sim "ensino de arte", todavia o teatro está entre as práticas artísticas nas escolas, dividindo com as outras que se faziam presentes, mas em todas as práticas se denotava a falta de preparaçáo dos professores. Segundo Japiassu (2001) a falta de formação dos professores em teatro também compactua para ele ser utilizado como um momento de lazer, entretenimento, esquecendo do real valor formativo.

Os Parâmetros Curriculares Nacionais de Arte (PCN, 2002, p. 15):

Foram constituídos a partir de estudos e discussões que versavam sobre dois aspectos básicos desta área de conhecimento: a natureza e a abrangência da educaçáo de artes e as práticas educativas e estéticas que vêm ocorrendo principalmente na escola brasileira.

Para os PCN de Arte (2002), as apreciações artísticas mediam formas diferentes de se perceber, sentir, articular significados e valores estabelecidos na relação entre sujeito e sociedade.

Os PCN de Artes têm por objetivo estabelecer uma referência curricular e apoiar a revisáo e/ou a elaboração da proposta curricular dos estados ou das escolas integrantes dos sistemas de ensino e foram lançados inicialmente em fascículos ao longo do ano de 1998. Segundo os PCN de Artes, os professores deviam adaptar os parâmetros à realidade de suas escolas e alunos. Os PCN 
de Artes são categorizados por ciclos na educação básica, ou seja, $1^{\circ}$ ciclo ( $1^{\circ}$ e $2^{\circ}$ séries), $2^{\circ}$ ciclo ( $3^{\circ}$ e $4^{\circ}$ séries), $3^{\circ}$ ciclo ( $5^{\circ}$ e $6^{\circ}$ séries $)$ e $4^{\circ}$ ciclo (70 e $8^{\circ}$ séries) e os PCN do Ensino Médio.

Os PCN de Artes da Educação Infantil discutem as possibilidades de trabalhar a arte com as crianças para que elas comecem a desenvolver habilidades motoras e cognitivas (BRASIL, 1998a). Segundo as Diretrizes Curriculares Nacionais para a Educação Infantil (DCNEI, 2009), a participação das artes é de extrema importância na vida do ser humano por propiciar experiências e permitir ao aluno desenvolver uma ampliação sobre o domínio das linguagens. A arte é para que:

I - promovam o conhecimento de si e do mundo por meio da ampliaçáo de experiências sensoriais, expressivas, corporais que possibilitem movimentaçáo ampla, expressáo da individualidade e respeito pelos ritmos e desejos da criança; II - favoreçam a imersão das crianças nas diferentes linguagens e o progressivo domínio por elas de vários gêneros e formas de expressão; gestual, verbal, plástica, dramática e musical. IX - promovam o relacionamento e a interaçáo das crianças com diversificadas manifestaçóes de música, artes plásticas e gráficas, cinema, fotografia, dança, teatro, poesia e literatura (art. $9^{\circ}$, grifo nosso).

Para os PCN de Artes do Ensino Fundamental (1998, p. 88), "o teatro é um conhecimento específico, mas pode chegar à escola de maneira espontânea, a partir do momento que se propóe trabalhar como um instrumento metodológico para diversificar a maneira que tem de ensinar algum conteúdo operando de modo coletivo"; de maneira que esse ensino possa intensificar as relaçóes dos indivíduos, tanto no mundo interior quanto exterior.

Ensinar teatro na escola é preparar os alunos para interagir com o mundo, perceber a sociedade e outras culturas (BRASIL, 2000). Além disso, espera-se que o aluno seja capaz de realizar:

- Observação, apreciação e análise das diversas manifestações de teatro. As produçóes e as concepções estéticas. 
- Compreensão, apreciação e análise das diferentes manifestaçóes dramatizadas da regiáo.

- Reconhecimento e compreensão das propriedades comunicativas e expressivas das diferentes formas dramatizadas (teatro em palco e em outros espaços, circo, teatro de bonecos, manifestações populares dramatizadas, etc.).

- Identificação das manifestaçóes e produtores em teatro nas diferentes culturas e épocas.

- Pesquisa e leitura de textos dramáticos e de fatos da história do teatro.

- Pesquisa e frequência junto aos grupos de teatro, de manifestação popular e aos espetáculos em sua região.

- Pesquisa e frequência às fontes de informaçóes, documentação e comunicação presentes em sua regiáo (livros, revistas, vídeos, filmes, fotografias ou qualquer outro tipo de registro em teatro).

- Elaboração de registros pessoais para sistematizaçáo das experiências observadas e da documentação consultada. (BRASIL, 2000, p. 88).

Os PCN de Artes do Ensino Fundamental que se referem a $1^{\mathrm{a}}$ e a $8^{\mathrm{a}}$ séries destacam o papel importante da arte para a vida do indivíduo. Para o documento, a arte permite uma aproximação entre os indivíduos, mesmo que as culturas sejam distintas, favorecendo a percepção das semelhanças e das diferenças entre as culturas, expressas em produtos artísticos e concepçóes estéticas em diferentes planos estéticos (BRASIL, 1998b).

Acreditando nisso, o documento propõe que a escola tenha a função de compartilhar os conhecimentos e que a disciplina de arte medeie o processo humanizador, cultural e histórico e potencialize a criação singular da imaginação humana.

Os PCN afirmam que a arte propóe um resgate da experiência como resultado das atividades envolvidas na vida inteira, sendo essa permissão a continuidade da tradição e dela própria. Considera-se que a aprendizagem artística envolve diferentes tipos de conhecimentos, mesmo que isso venha gerar significaçóes e exercícios do aluno para que haja o desenvolvimento da percepção como agente das transformaçóes (BRASIL, 1998b). 
Os PCN de Arte do Ensino Médio (2000) indicam a importância de os alunos se apropriarem dos saberes culturais e estéticos inseridos nas práticas de produção e apreciações artísticas que são fundamentais para a formação social do cidadáo. Segundo o documento, a inserção da arte como disciplina obrigatória contribui para o fortalecimento da experiência sensível e inventiva dos alunos, e associa o exercício da cidadania, das diversas práticas e conhecimentos humanos, possibilitando apreciações em diversas linguagens artísticas.

Para o documento, a partir da obrigatoriedade da arte, há o tencionamento do fortalecimento desse saber enquanto disciplina escolar, no intuito de ajudar nas práticas pedagógicas, expondo o sentido do ensino e da aprendizagem das linguagens artísticas que permeia a teoria e a prática e desenvolve os conhecimentos dos indivíduos (BRASIL, 1998).

Os PCN - 1998 consideram que a arte é uma linguagem que envolve a música, as artes visuais, a dança, o teatro e as artes audiovisuais. Dessa forma, ela permite ao indivíduo realizar produçóes individuais e/ou coletivas que possibilitem a análise, a reflexão e a compreensão das manifestações socioculturais e históricas, não instigando a dicotomia entre teoria e prática e pensar e agir (BRASIL, 1998).

Segundo o documento, a perspectiva de ensino do teatro que não suprima a historicidade que possibilita ter referências pela velocidade da informação é fundamental. Essa proposta educativa fundamenta o desenvolvimento de habilidades e comportamentos inseridos numa arte-educação contextualizada (BRASIL, 1998) que contribua para outras formas de apreender a realidade.

Segundo Cavassin (2008), embora o ensino da arte envolva muitas polêmicas e problemas de aceitação nas escolas, a arte é uma forma de conhecimento que envolve a história, a vida e a sociedade, sendo efetiva na educação formal.

No âmbito dos cursos de graduação em Teatro, pode-se afirmar que o Teatro foi aprovado oficialmente para curso superior a partir da Lei 9.131, em 24/11/1995, assim como as outras habilidades artísticas (Dança, Música e Design), ao ser reformulada para o art. $9^{\circ}$, inciso $2^{\circ}$, alínea "c", da então LDB 4.024/61, e que conferia pela Câmara de Educação Superior Nacional de Educação a competência para a elaboração das Diretrizes Curriculares Nacionais dos Cursos de Graduação em Música, Dança, Teatro e Design (DCN, 2003). 
As DCN 9.131 dos cursos de graduação em Teatro orientam para o desenvolvimento de competências e habilidades para o conhecimento da linguagem teatral, da história do teatro, da dramaturgia, da literatura dramática, bem como para o domínio dos códigos da encenação, interpretação, criação do espetáculo teatral incluindo a composição dos elementos visuais (BRASIL, 2004).

O ensino do Teatro propõe que se trabalhe a comunicação humana em suas diferentes formas de expressão, seja quaisquer quer for. Segundo as DCN 9.131, não precisa apenas ser graduado em Teatro para ensinar no âmbito formal ou não formal, mas precisa ter os requisitos básicos das competências e habilidades ligadas à arte cênica. Para a Lei no 9.394/94, nas licenciaturas prevê a obrigatoriedade das artes nas escolas, oportunizando assim um ensino voltado para a formação humana.

As diretrizes não são exclusivamente para professores formados em Arte, mas envolve indicaçóes para os professores em geral:

[...] capacitaçáo para a apropriação do pensamento reflexivo e da sensibilidade artística, compreendendo sólida formação técnica, artística, ética e cultural, com aptidão para construir novas formas de expressão e de linguagem corporal e de propostas estéticas, inclusive como elemento de valorização humana e da autoestima, visando a integrar o indivíduo na sociedade e tornando-o participativo de suas múltiplas manifestaçóes culturais. (BRASIL, 2004, p. 2).

As DCN 9.131 explicitam no art. 12 que "os cursos de graduação em Teatro para formação de docentes, licenciatura plena, deverão observar as normas específicas relacionadas a essa modalidade de oferta” (BRASIL, 2004, p. 3) para ter habilitação.

Em 2016 se definem melhor as linguagens artísticas que envolvem o ensino de artes: "As artes visuais, a dança, a música e o teatro são as linguagens que constituirão o componente curricular" (Redaçáo dada pela Lei no 13.278, de 2016). Assim tem-se uma base para a necessidade de os professores saírem da polivalência do ensino da arte e buscarem o aprofundamento do conhecimento nos cursos específicos. 


\section{Ponderações sobre a institucionalização do ensino do teatro na educação escolar}

Pode-se perceber que no Brasil a arte já funcionou como metodologia, como um recurso atraente para a incorporação da ideologia dominante, para tornar a catequização dos índios mais fácil, ocultando a dominação a que estavam submetidos. Esse reducionismo exclui a capacidade de a arte ter autonomia e finalidade em si, já que reforça a mera reproduçáo da dominação e a finalidade é totalmente externa: catequização.

Quando a arte objetiva desenvolver habilidades manuais para o trabalho e a capacidade dos alunos para realizar a mera reproduçáo de um modelo, ou seja, uma cópia, também reduz as suas potencialidades de transcendência, de se realizar uma experiência estética e de carregar a universalidade da humanidade.

Se não há possibilidade de reconhecimento da historicidade de qualquer obra, se restringe a capacidade do sujeito de se reconhecer e reconhecer o outro, reconhecer a arte como um produto cultural humano que carrega o presente, o passado e o futuro. Nesse contexto, o sentido é imposto e tem que ser perpetuado estando mais próximo do fetiche de uma produção, do estranhamento em Marx do que do reconhecimento. Sem contar que sua finalidade está em ser funcional para as demandas da sociedade vigente, ou seja, em desenvolver movimentos precisos e repetidos que se reproduzam em série para a adaptação.

A finalidade externa de apresentação em festas ou para aproximar a família, a comunidade da escola também nega o que seria arte em seu sentido pleno, já que para Kant a finalidade em si da arte daria a ela a autonomia de não atender às exigências externas de uma determinada sociedade, governo ou indivíduo.

Ao mesmo tempo o ensino da arte como instrumento que deve ser aplicado conforme o contexto em outras disciplinas realiza o primado da instrumentalização, da funcionalidade presente na sociedade capitalista, além de reduzir a arte de uma área do conhecimento, de um fundamento da educação, a uma metodologia que não pode apresentar um caráter mais amplo de formação.

A polivalência é tributária da má-formação dos professores, deixando espaço para que qualquer pessoa possa ensinar a arte ou para que possa se 
conceber o ensino da arte como menos importante do que o ensino de outras áreas do saber.

Esses elementos e mais alguns que não foram desenvolvidos aqui são parceiros da dificuldade de se entender a arte como fundamento da educação, como um produto cultural artístico que realiza a formação do sujeito.

A arte precisa provocar rupturas nas regras fixas da sociedade para que permita que o espectador possa ter experiência estética transformadora que rompa com a passividade.

Para Adorno, em contrapartida, a filosofia tem a tarefa de conhecer o que não é mais, ou seja, de descobrir por que foram vedadas as possibilidades segundo as quais seria possível instituir uma vida melhor aqui e agora, respondendo por que a humanidade, como se lê no começo da Dialética do Esclarecimento, "em vez de entrar em um estado verdadeiramente humano, está se afundando em uma nova espécie de barbárie”. (DUARTE, 2004, p. 140).

Nesse sentido, a arte é autônoma. A arte parte da realidade, mas dela se afasta e quando não realiza isso é mera reprodução e tende a formar um sujeito passivo, que não reflete a sociedade.

Que as obras de arte, como mônadas sem janelas, representem o que elas próprias não são, só pode compreender pelo fato de que a sua dinâmica própria, a sua historicidade imanente enquanto dialética da natureza e do domínio da natureza não é a da mesma essência que a dialética exterior, mas se lhe assemelha em si, sem imitar (ADORNO, 1970, p. 16).

Nesse contexto, é preciso ter cuidado para não instrumentalizar a capacidade do pensamento. A ascensão da razão subjetiva estabelece o declínio do sujeito, pois:

[...] relaciona-se essencialmente com meios e fins, com a adequação de procedimentos a propósitos mais ou menos tidos como certos e que se presumem auto-explicativos. Concede pouca importância à indagação de se os propósitos como tais 
são racionais. Se essa razão se relaciona de qualquer modo com os fins, ela tem como certo que estes são também racionais no sentido subjetivo, isto é, de que servem ao interesse do sujeito quanto à autopreservação - seja o indivíduo isolado ou da comunidade de cuja subsistência depende a preservação do indivíduo (HORKHEIMER, 2013, p. 9, 10).

Max Horkheimer (2013, p. 27) acredita que:

Quanto mais as ideias se tornam automáticas, instrumentalizadas, menos alguém vê nelas pensamentos com um significado próprio. A linguagem tornou-se apenas mais um instrumento no gigantesco aparelho de produção da sociedade moderna.

A instrumentalização afasta a possibilidade de autonomia da razão, perde a capacidade da razão de se exercer como racional.

A ideia de que um objetivo possa ser racional por si mesmo fundamentada nas qualidades que se podem discernir dentro dele - sem referência à qualquer espécie de lucro ou vantagem para o sujeito, é inteiramente alheia à razão subjetiva, mesmo quando esta se ergue acima da consideração de valores utilitários imediatos e se dedica a reflexóes sobre ordem social como um todo. (HORKHEIMER, 2013, p. 10).

O núcleo da experiência na e da arte reside na compreensão do presente como histórico e na recusa de um curso pré-traçado para a história, atribuindo-lhe um sentido emancipatório construído a partir da elaboração de um passado que parece fixado e determinado apenas como garantia de sua continuidade, cujo curso precisa ser rompido em suas condiçóes sociais e objetivas (ADORNO, 1995, p. 12, 13).

Segundo Maar (1995, p. 27), Adorno afirma que "é preciso romper com a educação enquanto mera apropriação de instrumental técnico e receituário para a eficiência, insistindo no aprendizado aberto à elaboraçáo da história e ao contato com o outro não-idêntico, o diferenciado". O autor reconhece os limites da educação, mas mesmo assim a coloca como uma dimensão importante. 
Nesse sentido, é necessário se interrogar se o ensino do teatro ainda guarda resquícios de ser instrumentalizado para o ensino de uma outra disciplina, para adestrar indivíduos, tornando-os mais animados ou calmos, se a finalidade máxima do ensino do teatro vem sendo fazer um espetáculo no final da disciplina e se vem sendo uma prática pedagógica para o desenvolvimento de competências e habilidades demandadas na sociedade atual. Estas, como outras questôes, como a formação do professor, são fundamentais serem investigadas.

\section{REFERÊNCIAS}

ADORNO, Theodor W. Educaçáo e Emancipaçáo. Rio de Janeiro: Paz e Terra, 1995. . Teoria Estética. Lisboa: Editora 70, 1970. p. 16.

Teoria da semicultura. Educaçáo \& Sociedade, Campinas-SP, ano 17, n. 56, p. 388-411, dez. 1996. (Original publicado em 1959).

BARBOSA, Ana Mãe. Arte - Educaçáo no Brasil. São Paulo: Perspectiva, 2005. p. 32.

BARBOSA, Pedro. Teoria do teatro moderno: axiomas e teoremas. Ediçóes: Afrontamento, Porto, 1982.

BENJAMIN, Walter. A obra de arte na época de sua reprodutibilidade técnica. 2. reimp. Porto Alegre, RS: Zouk, 2012.

BERTHOLD, Margot. História mundial do teatro. São Paulo: Perspectiva, 2000. p. 1.

BLOT, Bernard. O teatro. In: PORCHER, Luis (Org.). Educaçáo Artística: luxo ou necessidade? Sáo Paulo: Summus, 1982.

BOAL, Augusto. O teatro do oprimido e outras poéticas. 4. ed. Rio de Janeiro: Civilizaçáo Brasileira, 1983.

. A estética do oprimido. Rio de Janeiro: Garamond, 2009.

BRASIL. Conselho Nacional de Educação. Câmara de Educação Superior. Diretrizes Curriculares Nacionais do Curso de Graduaçáo em Teatro. Brasília, 8 de março de 2004. . Conselho Nacional de Educação. Conselho Pleno. Diretrizes Curriculares Nacionais para a Formaçáo de Professores da Educaçáo Básica. Brasília, 18 de fevereiro de 2002. . Ministério da Educaçáo e do Desporto. Secretaria de Educação Fundamental. Parâmetros Curriculares Nacionais para o Ensino Fundamental. Primeiro e segundo ciclos do ensino fundamental: Arte. Brasília: MEC; SEF, 1997.

. Ministério da Educaçáo e do Desporto. Secretaria de Educação Fundamental. 
Parâmetros Curriculares Nacionais para o Ensino Fundamental. Terceiro e quarto ciclos do ensino fundamental: Arte. Brasília: MEC; SEF, 1998b.

- Ministério da Educação e do Desporto. Secretaria de Educação Fundamental. Parâmetros Curriculares Nacionais: Ensino Médio. Brasília, 2000.

Ministério da Educação e do Desporto. Secretaria de Educação Fundamental. Referencial curricular nacional para a educaçáo infantil. Conhecimento de mundo. Brasília, 1998a. v. 3.

BRECHT, Bertolt. Estudos sobre teatro - Bertolt Brecht. Rio de Janeiro: Nova Fronteira, 1978. p. 100-140.

CAVASSIN, J. Perspectivas para o teatro na educação como conhecimento e prática pedagógica. R. cient./FAP, Curitiba, v. 3, p. 39-52, jan./dez. 2008.

DUARTE, R. Teoria crítica da indústria cultural. Belo Horizonte: Editora UFMG, 2004. p. 140 .

FERREIRA, Luiz A. C. Processos teatrais na ação educativa. In: FERREIRA, Maria L. M. (Org.) A Arte como processo na educaçáo. Rio de Janeiro: Funarte, 1982. p. 82.

JAPIASSU, Ricardo. Metodologia do ensino de teatro. Campinas: Papirus, 2001.

KOUDELA, Ingrid. Jogos teatrais. São Paulo: Perspectiva, 1990.

MAGALDI, Sábato. Panorama do teatro brasileiro. Global Editora, 1978.

MARCUSE, Herbert. Cultura e Sociedade. v. 2. São Paulo: Paz e Terra, 1998. p. 153-175.

MAROCCO, I. A. Aventuras na Academia: Reflexóes sobre uma prática artística/pedagógica. In: TAVARES, Enéias; MAGNO, M.; BIANCANA, G. (Org.). Discursos do Corpo na Arte II. 1. ed. Santa Maria: UFSM, 2015. p. 5-120.

REVERBEL, O. Um caminho do teatro na escola. São Paulo: Scipione. 2. ed. 1997.

SOARES, C. Pedagogia do jogo Teatral: uma poética do efêmero - O ensino do teatro na escola pública. São Paulo: Editora Hucitec, 2009. p. 41.

TELLES, Narciso. Teatralidade e a pedagogia do ator horizontal. In: TAVARES, Renan (Org.). Entre coxias e recreios: recortes da produção carioca sobre o ensino do teatro. São Caetano do Sul, SP: Yendis Editora, 2006. 